\title{
A randomised controlled study for the prevention of post-partum haemorrhage with oxytocin plus methyl ergometrine versus oxytocin alone in the third stage of labour
}

\author{
Rajani Somanathan $^{1 *}$, Mohanapriya Balu ${ }^{1,2}$, Elizabeth Jacob $^{1}$, Sr Marykutty Illickal $^{1}$
}

\begin{abstract}
${ }^{1}$ Department of Obstetrics and Gynaecology, Little Flower Hospital and Research Centre, Angamaly, Kerala, India ${ }^{2}$ Department of Obstetrics and Gynaecology, Sri Ramakrishna Hospital, Coimbatore, Tamil Nadu, India
\end{abstract}

Received: 18 February 2021

Accepted: 31 March 2021

*Correspondence:

Dr. Rajani Somanathan,

E-mail: kuttu2412@gmail.com

Copyright: (c) the author(s), publisher and licensee Medip Academy. This is an open-access article distributed under the terms of the Creative Commons Attribution Non-Commercial License, which permits unrestricted non-commercial use, distribution, and reproduction in any medium, provided the original work is properly cited.

\begin{abstract}
Background: Postpartum haemorrhage is the leading cause of maternal death. Uterine atony which is preventable, causes $80 \%$ of Post partum haemorrhage (PPH). Active management of third stage of labour (AMTSL) lowers maternal blood loss and reduces the risk of PPH. In this open labelled randomised controlled study we compared the combined use of oxytocin and methyl ergometrine vs oxytocin alone in prevention of PPH in the third stage of labour.

Methods: 200 Women admitted for safe confinement and following the inclusion criteria were randomised immediately post delivery to receive either oxytocin +methyl ergometrine or oxytocin alone. The amount of blood loss was assessed objectively by weighing the mops and under sheets used during delivery. If bleeding could not be controlled, additional uterotonics were given. The incidence of PPH, amount of blood loss, use of additional uterotonics and side effects were recorded. The difference in pre natal and post natal haemoglobin $(\mathrm{Hb})$ and the need for blood transfusion were assessed. Results: There was no statistically significant difference in the incidence of PPH between the groups. Post partum blood loss was significantly lesser in the combined group. Additional oxytocics were required more often in the oxytocin only group. The incidence of headache was significantly more in the combined group. The difference in haemoglobin levels post natally and the need for blood transfusion was comparable among both groups.

Conclusions: The combined use of methyl ergometrine +oxytocin is not recommended over oxytocin alone in the third stage of labour for prevention of PPH.
\end{abstract}

Keywords: Post-partum haemorrhage, PPH, Oxytocin, Methyl ergometrine

\section{INTRODUCTION}

Maternal mortality is a major indicator of the health status of a country. Maternal mortality ratio in India is 122 in 2015 to 2017. The maternal mortality in Kerala is 42 in 2015 to $2017 .{ }^{1}$ The goal 3 of Sustainable development goals targets to bring down MMR below 70 by $2030 .^{2}$ The Surakshit matritva aashwasan initiative (SUMAN) aims at zero preventable maternal and newborn deaths. ${ }^{3}$

Primary post-partum haemorrhage is a blood loss of more than $500 \mathrm{ml}$ within $24 \mathrm{~h}$ of giving birth. It is the leading cause of maternal death worldwide accounting for $27 \%$ and causing about $1,00,000$ deaths per year. Uterine atony which is preventable, causes $80 \%$ of PPH. Active management of third stage of labour lowers maternal blood loss and reduces the risk of PPH. It consists of uterotonics, controlled cord traction, uterine massaging., ${ }^{4,5}$ A $40 \%$ reduction in the risk of $\mathrm{PPH}$ has been noted with the prophylactic use of oxytocics. Oxytocin and ergot alkaloids are the commonly used oxytocics. ${ }^{6}$

In this randomised controlled trial, the effect of combined use of oxytocin plus methyl ergometrine versus oxytocin 
alone in prevention of PPH in the third stage of labour was analysed. The hypothesis of the study was that the combined use of the drugs is more effective than oxytocin alone.

\section{Aim}

To compare the efficacy of combined use of oxytocin plus methyl ergometrine versus oxytocin alone in 3rd stage of labour for the prevention of PPH.

\section{Primary objectives}

To compare the incidence of PPH in combined use of methyl ergometrine vs oxytocin alone in the third stage of labour.

\section{Secondary objectives}

To compare the amount of blood loss in both groups, to compare the requirement for additional oxytocics in both groups and to compare the side effects in both groups.

\section{METHODS}

\section{Study site}

Inpatients in the Department of Obstetrics and Gynaecology, Little Flower Hospital and research centre, Angamaly.

\section{Study population}

Women admitted for safe confinement who fulfil the inclusion criteria of the study and give informed written consent for the same.

\section{Study design}

This is an open labelled randomised controlled study.

\section{Study duration}

October 2018 to May 2019 for 8 months.

\section{Inclusion criteria}

Willing to participate, age 20-35 years, gestational age-37 weeks-40 weeks, singleton, onset-spontaneous/induced, birth weight of baby-2-4 $\mathrm{kg}$ and patients undergoing FTND with RMLE.

\section{Exclusion criteria}

Hypertensive, allergy to Methyl ergometrine, previous CS, previous uterine surgery like myomectomy, more than 3 previous vaginal deliveries, vaginal tears during delivery, history of APH, PPH, bleeding disorders, blood coagulation abnormalities, pre delivery $\mathrm{Hb}<9 \mathrm{gm} \%$, intrapartum fever, multiple pregnancy, malpresentation, cervical tears, traumatic PPH, instrumental delivery, caesarean section, prolonged labour, oligohydramnios/polyhydramnios, fibroid complicating pregnancy, chorioamnionitis and intra uterine death.

\section{Statistical methods}

Descriptive and inferential statistical analysis done. Results on continuous measurements was assessed as Mean \pm SD (minimum to maximum) and categorical measurements in Number (\%). Significance is assessed at $5 \%$ level of significance. Student $\mathrm{t}$ test (two tailed, independent) was used for continuous scale between two groups (Inter group analysis) on metric parameters. Leven's test for homogeneity of variance was used to assess the homogeneity of variance. Chi-square/ Fisher Exact test was used to find the significance of study parameters on categorical scale between two or more groups, Non-parametric setting for qualitative data analysis. Fisher exact test was used when cell samples are very small.

\section{Significant figures}

+ Suggestive significance $(\mathrm{p}$ value: $0.05<\mathrm{p}<0.10)$

* Moderately significant ( $\mathrm{p}$ value: $0.01<\mathrm{p} \leq 0.05$ )

$* *$ Strongly significant ( $\mathrm{p}$ value: $\mathrm{p} \leq 0.01$ )

\section{Statistical software}

The statistical software namely statistical package for social sciences (SPSS) 18.0, and R environment version 3.2.2 were used for the analysis of the data and microsoft word and excel have been used to generate graphs, tables etc.

\section{Methodology and data collection}

200 antenatal women who were admitted for safe confinement and fulfilled the inclusion criteria and were either in spontaneous or induced labour were selected for the study. History was taken and examination done. Pre labour haemoglobin levels were tested. Foetal heart sound was monitored by intermittent Doppler or by continuous electronic foetal monitoring. Labour progress was monitored using partogram. Prolonged and precipitate labour was excluded from the study, If the patient was taken up for caesarean she was excluded from the study.

In the second stage the patient is shifted to 2nd stage labour room and the delivery conducted by the resident Doctor. If there is instrumental delivery, shoulder dystocia, or vaginal or cervical tears, the patient was excluded from the study. Only FTND with RMLE or first or second degree 
perineal tear were included in the study. Randomisation was done immediately post-delivery.

Randomisation was done using sequentially numbered opaque, sealed, and stapled envelopes. These envelopes were made at the commencement of the trial itself.100 A4 sheets each were typed with group A and 100 such with group B. Group A was the combined oxytocin+methyl ergometrine group and group B was the oxytocin only group. These A4 sheets were folded and placed in to sealed envelopes and arranged in a random sequence. 200 such sequentially numbered sealed, opaque envelopes were made and kept in a box in the 2nd stage of labour room. The envelope was opened immediately post-delivery of the baby by the labour room incharge nurse and the patient allocated to group A or group B accordingly. The next envelope was not to be opened priorly or read priorly or held to the light to read the information in it earlier itself. This was conducted as an open labelled study and hence blinding was not done.

Delayed cord clamping was done except in situations where early clamping is indicated. Immediately after delivery of the baby, the patient in oxytocin only group was administered 10 units oxytocin IM according to the ACOG Practice Bulletin number 183, October 2017 and WHO Recommendations for active management of the third stage of labour, 2012. ${ }^{7,5}$

The patient who was randomised in the combined oxytocin plus methyl ergometrine group received methyl ergometrine $0.2 \mathrm{mg}$ slow IV in addition to 10 units oxytocin IM. The drug administration was done by the senior nursing staff under supervision by the resident Doctor. Uterine massaging was done.

The placenta was delivered by controlled cord traction. The under pad was changed immediately following placental delivery. Vagina and cervix are assessed for tears. The episiotomy was sutured in layers under local anaesthesia. Vitals were assessed immediately following delivery and then hourly for 2 hours. The blood loss was assessed by weighing the undersheet and mops with the weighing scale. The weight of blood measured in grams is equal to the amount of blood loss in ml (Figure 1 and 2). This was recorded by the resident doctor. The total blood loss was calculated and recorded.

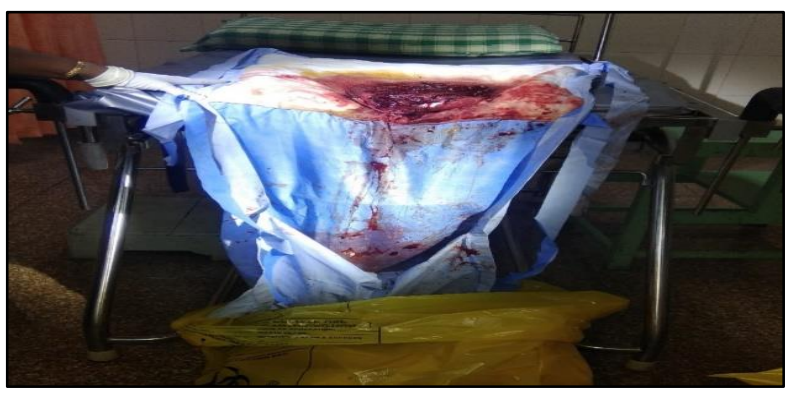

Figure 1: Blood loss estimation: draw sheets used.

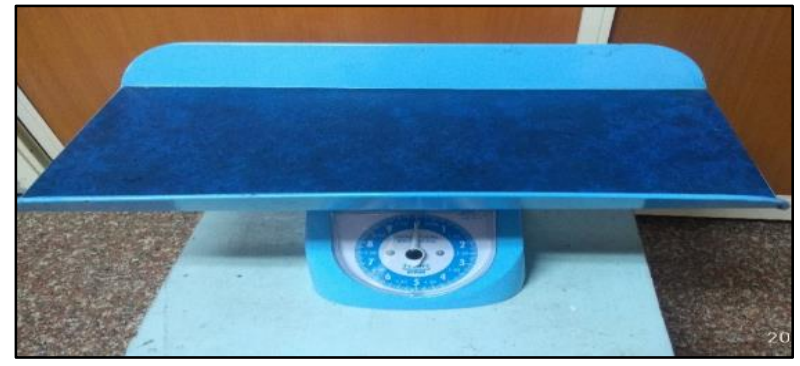

Figure 2: Weighing scale used.

At any point if there was uterine relaxation or increased bleeding, additional oxytocics and/or blood transfusion was done as needed for stabilizing the patient. All the details of drug administration were accurately documented in the proforma. For these 2 hours, the patient was also assessed for the side effects of fever, nausea, vomiting, headache, raise in BP and shivering. After monitoring for 2 hours the patient was shifted to the ward if stable.

$\mathrm{Hb}$ was reassessed on post-natal day 2 and recorded. The need for blood transfusion was recorded. Patient was discharged on post-natal day 3 if stable.

The data was entered in MS Excel from the proforma and statistically analysed with the help of a statistician with the use of software SPSS 18.0, to reach a conclusion after completion of the study period.

\section{RESULTS}

Baseline characteristics were comparable among both groups with regard to age, gestational age, body mass index, obstetrics score, mode of onset of labour, birth weight of baby.

The mean blood loss was $317.7 \pm 102.4 \mathrm{ml}$ in the combined methyl ergometrine+ oxytocin group and $413.6 \pm 129.39 \mathrm{ml}$ in the oxytocin only group. The blood loss in the combined methyl ergometrine +oxytocin group was significantly less than the oxytocin only group with a $p$ value of 0.001 . Thus showing that the combined use the drugs is more effective in decreasing the amount of blood loss post delivery. (Table 1 and Figure 3).

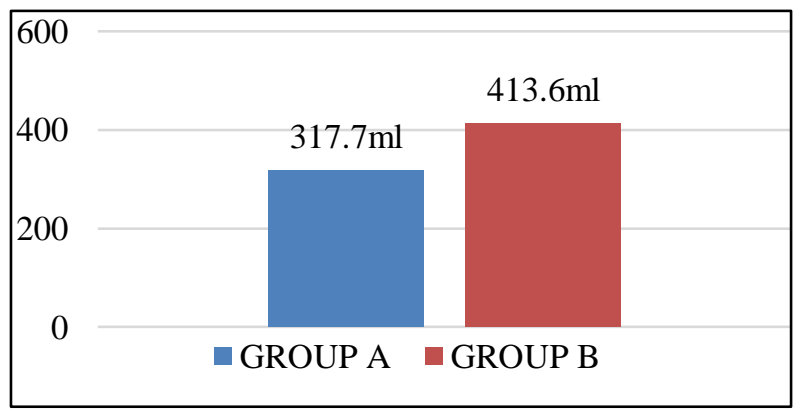

Figure 3: Comparison of mean blood loss between the combined oxytocin +methyl ergometrine group (group A) and the oxytocin only group (group B). 
Post-partum haemorrhage was seen more commonly in the oxytocin only group with an incidence of $3 \%$ (6 cases of $\mathrm{PPH})$. It was less common in the combined methyl ergometrine+oxytocin group with an incidence of $1.5 \%$ (3 cases). The difference in the incidence of PPH was not statistically significant between the 2 groups with a p value of 0.306 . Thus it was observed that the combined use of methyl ergometrine+oxytocin is not more effective than oxytocin alone for the prevention of PPH. (Table 2). 3 patients in the combined methyl ergometrine+oxytocin group had mild PPH and 5 patients in the oxytocin only group had mild PPH. The incidence of mild PPH was comparable between both the groups with an insignificant $\mathrm{p}$ value of 0.4 .

Table 1: Comparison of blood loss between the combined oxytocin +methyl ergometrine group (group A) and the oxytocin only group (group B).

\begin{tabular}{|llll|}
\hline Blood loss & Group A & Group B & P value, student t test \\
\hline$<\mathbf{3 0 0}$ & $47(47 \%)$ & $15(15 \%)$ & \\
\hline $\mathbf{3 0 0 - 5 0 0}$ & $50(50 \%)$ & $79(79 \%)$ & \\
\hline$>\mathbf{5 0 0}$ & $3(3 \%)$ & $6(6 \%)$ & $<0.001$ (significant) \\
\hline Mean $\mathbf{E S D}$ & $317.70 \pm 102.14$ & $413.60 \pm 129.39$ & \\
\hline
\end{tabular}

Table 2: Comparison of incidence of PPH between the combined oxytocin +methyl ergometrine group (group A) and the oxytocin only group (group B).

\begin{tabular}{|llll|}
\hline PPH & Group A & Group B & $\begin{array}{l}\text { P value } \\
\text { Fisher Exact Test }\end{array}$ \\
\hline No & $97(97 \%)$ & $94(94 \%)$ & 0.306 \\
\hline Yes & $3(3 \%)$ & $6(6 \%)$ & 0.06 \\
\hline
\end{tabular}

Table 3: Comparison need for additional oxytocics between the combined oxytocin +methyl ergometrine group (group A) and the oxytocin only group (group B).

\begin{tabular}{|lllll|}
\hline $\begin{array}{l}\text { Additional oxytocics } \\
\text { used }\end{array}$ & $\begin{array}{l}\text { Group A } \\
(\mathbf{n = 1 0 0 )}\end{array}$ & $\begin{array}{l}\text { Group B } \\
(\mathbf{n = 1 0 0 )}\end{array}$ & $\begin{array}{l}\text { Total } \\
(\mathbf{n = 2 0 0 )}\end{array}$ & P value \\
\hline Oxytocin & $11(11 \%)$ & $22(22 \%)$ & $33(16.5 \%)$ & $0.036^{*}$ \\
\hline Methyl ergometrine & $6(6 \%)$ & $13(13 \%)$ & $19(9.5 \%)$ & $0.091+$ \\
\hline Misoprostol & $9(9 \%)$ & $21(21 \%)$ & $30(15 \%)$ & 0.017 (significant) \\
\hline Tranexemic acid & $5(5 \%)$ & $10(10 \%)$ & $15(7.5 \%)$ & 0.179 \\
\hline PGF2alpha & $3(3 \%)$ & $4(4 \%)$ & $7(3.5 \%)$ & 1.000 \\
\hline
\end{tabular}

Table 4: Comparison of the side effects between the combined oxytocin +methyl ergometrine group (group A) and the oxytocin only group (group B).

\begin{tabular}{|lllll|}
\hline Shivering & $\begin{array}{l}\text { Group A } \\
(\mathbf{n = 1 0 0 )}\end{array}$ & $\begin{array}{l}\text { Group B } \\
(\mathbf{n = 1 0 0 )}\end{array}$ & $\begin{array}{l}\text { Total } \\
(\mathbf{n = 2 0 0})\end{array}$ & P value \\
\hline Fever & $16(16 \%)$ & $25(25 \%)$ & $41(20.5 \%)$ & 0.115 \\
\hline Hypertension & $5(5 \%)$ & $10(10 \%)$ & $15(7.5 \%)$ & 0.179 \\
\hline Vomiting & $8(8 \%)$ & $2(2 \%)$ & $10(5 \%)$ & $0.052+$ \\
\hline Loose stool & $10(10 \%)$ & $5(5 \%)$ & $15(7.5 \%)$ & 0.179 \\
\hline Headache & $4(3 \%)$ & $2(2 \%)$ & $5(2.5 \%)$ & 1.000 \\
\hline
\end{tabular}

Table 5: Comparison of decrease in post natal $\mathrm{Hb}$ between the combined oxytocin + methyl ergometrine group (group A) and the oxytocin only group (group B).

\begin{tabular}{|lllll|}
\hline Hemoglobin $(\mathrm{g} / \mathrm{dl})$ & Group A & Group B & Total & P value \\
\hline Pre delivery & $12.13 \pm 0.95$ & $12.10 \pm 1.00$ & $12.12 \pm 0.97$ & 0.845 \\
\hline Post natal & $10.98 \pm 0.98$ & $10.81 \pm 1.18$ & $10.89 \pm 1.08$ & 0.252 \\
\hline Difference & $1.17 \pm 0.71$ & $1.30 \pm 0.69$ & $1.24 \pm 0.70$ & 0.206 \\
\hline
\end{tabular}


Table 6: Comparison of requirement of blood transfusion between the combined oxytocin + methyl ergometrine group (group A) and the oxytocin only group (group B).

\begin{tabular}{|llll|}
\hline Blood & Group A & Group B & $\begin{array}{l}\text { P value } \\
\text { Fisher exact test }\end{array}$ \\
\hline No & $99(99 \%)$ & $98(98 \%)$ & \\
\hline Yes & $1(1 \%)$ & $2(2 \%)$ & $\mathrm{P}=1.000$ \\
\hline
\end{tabular}

None in the combined group and 1 in the oxytocin only group had severe PPH, the difference in the incidence of severe PPH was comparable between both the groups with an insignificant $\mathrm{p}$ value of 1 . Additional oxytocics were required more often in the oxytocin only group. Additional doses of oxytocin were the most commonly used additional drug. While only $11 \%$ in the combined oxytocin +methyl ergometrine group required additional doses of oxytocin, $22 \%$ in the oxytocin only group required additional doses of oxytocin. The difference in the need for additional oxytocin dose was statistically significant. Additional doses of methyl ergometrine was required in $6 \%$ of the patients in the combined group and $13 \%$ in the oxytocin only group, but the difference was not statistically significant. $9 \%$ in the combined group and $21 \%$ in the oxytocin only group required misoprostol. This requirement was seen significantly more common with a $\mathrm{p}$ value of 0.017 . Tranexemic acid was given in $5 \%$ in the combined group and in $10 \%$ in the oxytocin only group but the difference was not statistically significant. PGF2alpha was required for the management of $\mathrm{PPH}$ in $3 \%$ in the combined group and in $4 \%$ in the oxytocin only group, but the difference was not statistically significant. (Table 3).

The commonest side effect seen in the study was shivering, which was more common in the oxytocin only group (25\%) as compared to the combined group. (16\%). But there was no significant difference between the 2 groups.

Fever was also more often seen in the oxytocin only group $(10 \%)$ as compared to the combined group (5\%), but the difference was not statistically significant. Hypertension, vomiting, loose stools, headache were all common in the combined group than the oxytocin only group. Hypertension was observed in $8 \%$ in the combined group and $2 \%$ in the oxytocin only group. Vomiting was also more common in the combined drug group (10\%) than in the oxytocin only group $(5 \%)$. Loose stools were seen in $3 \%$ in the combined group and in $2 \%$ in the oxytocin only group. The differences were not statistically significant. Headache occurred significantly more often in the combined methyl ergometrine +oxytocin group (4\%) as compared to the oxytocin only group $(0 \%)$ (Table 4$)$.

All the patients who developed PPH in our study could be managed medically. Surgical management of PPH was not required in any of our patients.

The mean pre delivery haemoglobin levels in the combined methyl ergometrine+oxytocin group was 12.13 $\mathrm{g} / \mathrm{dl}$ and in the oxytocin only group was $12.1 \mathrm{~g} / \mathrm{dl}$ which was comparable. The mean post natal haemoglobin levels in the combined methyl ergometrine +oxytocin group were $10.98 \mathrm{~g} / \mathrm{dl}$ and in the oxytocin only group it was $10.81 \mathrm{~g} / \mathrm{dl}$ which was also comparable. The difference in $\mathrm{Hb}$ between pre and post natal was $1.17 \mathrm{~g} / \mathrm{dl}$ in the oxytocin+methyl ergometrine group and $1.3 \mathrm{~g} / \mathrm{dl}$ in the oxytocin only group. The difference in haemoglobin levels post delivery was not statistically significant. (Table 5)

3 patients in the study had PPH requiring blood transfusion.1 patient in the combined methyl ergometrine+oxytocin group and 2 patients in the oxytocin only group required blood transfusion. The difference in the requirement of blood transfusion was not statistically significant.

\section{DISCUSSION}

In our study the incidence of PPH was $3 \%$ in the combined oxytocin +methyl ergometrine group and $6 \%$ in the oxytocin only group. This was not statistically significant. Hence the use of methyl ergometrine+oxytocin is not more effective than using oxytocin alone according to our study.

The Cochrane meta analysis in 2004 concluded that the combination preparation of syntometrine as a part of the routine active management of third stage of labour is associated with a statistically significant reduction in the risk of PPH when compared to oxytocin. ${ }^{8}$

In a similar study by Nuamsiri et al, the prevention of postpartum haemorrhage with oxytocin versus ergometrine plus oxytocin in the third stage of labour was studied and the result was similar to our study with no significant difference in the incidence of PPH. There was $1 \mathrm{PPH}(0.6 \%)$ in the oxytocin only group and none in the combined group. The mean blood loss with combined use of the dugs was $145 \mathrm{ml}$ and with oxytocin alone it was $150 \mathrm{ml}$ which wasn't significant. None in the combined drug group and $1.2 \%$ in the oxytocin only group required additional oxytocics which was not statistically significant. Hypertension occurred significantly more often in the combined drug group $(6.2 \%$ versus $0 \%)$ with a $p$ value of 0.001 . Other side effects were comparable among both groups. The decrease in haemoglobin postnatally was $0.8 \mathrm{~g} / \mathrm{dl}$ in the combined oxytocin+methyl ergometrine group and $0.9 \%$ in the oxytocin only group. This difference was not statistically significant. The need 
for blood transfusion was $1.2 \%$ in the combined group and $0.6 \%$ in the oxytocin only group. ${ }^{9}$

In a study by Khooshideh et al a comparison between oxytocin and syntometrine for preventing post partum haemorrhage, it was seen that syntometrine significantly reduced the incidence of PPH as compared to oxytocin as opposed to our study. Side effects were uncommon and the incidence of hypertension was similar between both the groups. ${ }^{10}$

In another study by Gohil et al comparing the efficacy of misoprostol, oxytocin, methyl ergometrine, and ergometrine oxytocin in reducing blood loss, the incidence of PPH with misoprostol was $20 \%$, with oxytocin $10 \%$, with methyl ergometrine $4 \%$ and with oxytocin ergometrine $6 \%$. It was seen that methyl ergometrine significantly prevented PPH compared to the other groups as opposed to our study. They observed in their study, similar to our study, that there was a higher incidence of hypertension with the use of oxytocin+ergometrine and with ergometrine when compared to misoprostol, and oxytocin alone, though not statistically significant. The incidence of nausea and vomiting was significantly more in the methyl ergometrine+oxytocin group and methyl ergometrine group. The decrease in haemoglobin was 0.59 $\mathrm{g} / \mathrm{dl}$ in the combined oxytocin+methyl ergometrine group, $0.63 \mathrm{~g} / \mathrm{dl}$ in the oxytocin only group, $0.57 \mathrm{~g} / \mathrm{dl}$ in the ergometrine group, and $0.72 \mathrm{~g} / \mathrm{dl}$ in the misoprostol group. This difference was not statistically significant. Blood transfusion was needed in $4 \%$ in the combined methyl ergometrine+oxytocin group, $2 \%$ in the oxytocin only group, $2 \%$ in the methyl ergometrine group and $14 \%$ in the misoprostol group. Here the requirement for blood transfusion was significantly more in the misoprostol group, but comparable among the other groups. ${ }^{11}$

In another study by Arunadevi on the comparative efficacy of syntometrine vs oxytocin in the active management of third stage of labour the mean blood loss was $120 \mathrm{ml}$ in the combined group and $171 \mathrm{ml}$ in the oxytocin only group. Similar to our study, the difference was statistically significant showing that the combined use of the drugs was more effective than oxytocin alone. $2 \%$ in the oxytocin only group and none of the patients in the combined methyl ergometrine+oxytocin group required blood transfusion, which was not statistically significant. ${ }^{12}$

Table 7: Comparison with other studies.

\begin{tabular}{|c|c|c|c|c|}
\hline Study & Incidence of PPH & $\begin{array}{l}\text { Mean blood } \\
\text { loss }\end{array}$ & $\begin{array}{l}\text { Difference between } \\
\text { pre natal and post } \\
\text { natal hemoglobin }\end{array}$ & $\begin{array}{l}\text { Need for blood } \\
\text { transfusion }\end{array}$ \\
\hline Nuamsiri et al $^{8}$ & $\begin{array}{l}\text { Not significant } \\
\mathrm{p}-0.4\end{array}$ & Not significant & $\begin{array}{l}\text { Not significant } \\
\text { p-0.118 }\end{array}$ & $\begin{array}{l}\text { Not significant } \\
\text { p-0.5 }\end{array}$ \\
\hline Senturk et al ${ }^{12}$ & - & - & $\begin{array}{l}\text { Significant } \\
\text { p- } 0.001\end{array}$ & - \\
\hline Gohil et al ${ }^{10}$ & - & - & $\begin{array}{l}\text { Not significant } \\
\text { p-0.06 }\end{array}$ & - \\
\hline Arunadevi et al ${ }^{11}$ & - & significant & - & $\begin{array}{l}\text { Not significant } \\
\text { p-0.08 }\end{array}$ \\
\hline Khooshideh et al ${ }^{19}$ & $\begin{array}{l}\text { Significant } \\
\text { p- }<0.05\end{array}$ & - & - & - \\
\hline Our study & $\begin{array}{l}\text { Not significant } \\
\text { p-0.306 }\end{array}$ & significant & $\begin{array}{l}\text { Not significant } \\
\text { p-0.206 }\end{array}$ & $\begin{array}{l}\text { Not significant } \\
\text { p-1 }\end{array}$ \\
\hline
\end{tabular}

In a study by Senturk et al, the effect of the combined use of methylergonovine and oxytocin during caesarean section in the prevention of post-partum haemorrhage was studied. The difference in pre and post natal haemoglobin was 0.85 in the combined methyl ergometrine+oxytocin group and 1.05 in the oxytocin only group which was statistically significant, thus indicating that the blood loss was significantly lesser in the combined group. ${ }^{13}$

According to the Cochrane Review 2018, ergometrine plus oxytocin combination, carbetocin, and misoprostol plus oxytocin combination were more effective for preventing $\mathrm{PPH} \geq 500 \mathrm{ml}$ than the current standard oxytocin. Ergometrine plus oxytocin combination was more effective for preventing $\mathrm{PPH} \geq 1000 \mathrm{ml}$ than oxytocin.
Misoprostol plus oxytocin combination evidence is less consistent and may relate to different routes and doses of misoprostol used in the studies. However, there was a higher risk of significant side-effects with the two combination regimens. Carbetocin had the most favorable side-effect profile amongst the top three options; however, most carbetocin trials were small and at high risk of bias. ${ }^{14}$

When we look at the different guidelines for active management of third stage of labor, the NICE guidelines advises 10 units of oxytocin IM at the delivery of anterior shoulder or immediately after delivery of the baby. ${ }^{15}$ The ACOG recommends Oxytocin dilute IV infusion 10 units or IM infusion 10 units for AMTSL.7According to RCOG, it is 10 units oxytocin IM. ${ }^{16}$ The WHO advises 10 units 
oxytocin IM $/ \mathrm{IV}^{5}$ The KFOG recommends 5 units oxytocin diluted in $5 \mathrm{ml}$ NS slow IV over 5 sec+10 units $\mathrm{IM}+20$ units infusion in $500 \mathrm{ml} \mathrm{NS}$ at $1 \mathrm{drop} / \mathrm{sec} .{ }^{17}$

\section{Limitations}

Small sample size of 200 women with only 100 women in each group. This study was conducted in an urban setup with all available resources to prevent and manage $\mathrm{PPH}$ and its further complications, it may not be applicable in a rural setup where both oxytocin and methyl ergometrine may not be available for simultaneous usage for all patients.

\section{CONCLUSION}

There was no statistically significant difference in the incidence of PPH between the combined use of methyl ergometrine+ oxytocin and the use of oxytocin alone for the prevention of PPH in the third stage of labour. The post partum blood loss was significantly lesser in the combined methyl ergometrine +oxytocin group than the oxytocin only group. Additional oxytocics were required more often in the oxytocin only group. The need for additional dose of oxytocin and the need for misoprostol was significantly more in the oxytocin only group as compared to the combined methyl ergometrine+oxytocin group. The incidence of headache was significantly more in the combined methyl ergometrine+oxytocin group. All other side effects were comparable between both the groups. The difference in haemoglobin levels post natally was comparable among both groups. The need for blood transfusion for PPH management was comparable among both the groups. Thus, from our study, we can conclude that the combined use of methyl ergometrine +oxytocin is not more effective than oxytocin alone in the prevention of PPH in third stage of labour. Further multicentric studies with larger sample size over longer durations are required to bring about better recommendations for better prevention of $\mathrm{PPH}$.

\section{ACKNOWLEDGMENTS}

Special thanks to Dr Madhuranjini, former consultant, Little flower hospital, and Dr Kochuthresia puthumana, consultant, Little flower hospital. Data was analysed with the help of Dr. K. P. Suresh, scientist (biostatistics) National institute of veterinary epidemiology and disease informatics (NIVEDI), Bangalore.

Funding: No funding sources

Conflict of interest: None declared

Ethical approval: The study was approved by the Institutional Ethics Committee

\section{REFERENCES}

1. National Sample registration System (SRS) 20152017. https://censusindia.gov.in/vital_statistics/SRS_
Bulletins/MMR_Bulletin-2015-17.pdf. Last accessed on $18^{\text {th }}$ January, 2021

2. Sustainable development goals. https://sdgs.un.org/goals. Last accessed on

3. Surakiart matritva aashwasan initiative (SUMAN). https://suman.nhp.gov.in/. Last accessed on $18^{\text {th }}$ January, 2021.

4. WOMAN Trial Collaborators. Effect of early tranexamic acid administration on mortality, hysterectomy, and other morbidities in women with post-partum haemorrhage (WOMAN): an international, randomised, double-blind, placebocontrolled trial. Lancet. 2017;389(10084):2105-2116.

5. WHO recommendations for prevention of PPH. https://www.who.int/reproductivehealth/topics/mater nal_perinatal/pph-woman-trial/en/. Last accessed on $18^{\text {th }}$ January, 2021.

6. Fujimoto M, Takeuchi K, Sugimoto M, Maruo T. Prevention of postpartum hemorrhage by uterotonic agents: comparison of oxytocin and methylergometrine in the management of the third stage of labor. Acta obstetricia et gynecologica Scandinavica. 2006;85(11):1310.

7. ACOG recommendations for active management of third stage and prevention of PPH available at Practice Bulletin No. 183 Summary: Postpartum Hemorrhage. Obstetrics \& Gynecology. 2017;130(4):923-925.

8. McDonald SJ. Prophylactic ergometrine-oxytocin versus oxytocin for the third stage of labour. Cochrane database of systematic reviews. 2004(1).

9. Nuamsiri $T$, Kaewkiattikun K. Prevention of Postpartum Hemorrhage with Oxytocin versus Ergometrine Plus Oxytocin in the third stage of labor. Thai Journal of Obstetrics and Gynaecology. 2016;97103.

10. Khooshideh M, Shahriari A. A comparison between oxytocin and syntometrine for preventing postpartum hemorrhage. Med J Reprod Infertil. 2004;5(1):52-61.

11. Gohil JT, Tripathi B. A Study to Compare the Efficacy of Misoprostol, Oxytocin, Methylergometrine and Ergometrine-Oxytocin in Reducing Blood Loss in Active Management of 3rd Stage of Labor. The Journal of Obstetrics and Gynecology of India. 2011;61(4):408.

12. Aruna Devi, V. "Comparative efficacy of Syntometrine Versus Oxytocin in active management of Third Stage of Labour." PhD diss., Madras Medical College, Chennai, 2010. http://ijcrr.com/uploads/573_pdf.pdf. Last accessed on $18^{\text {th }}$ January, 2021.

13. Şentürk Ş, Kağıtçı M, Balık G, Arslan H, KırŞahin F. The Effect of the Combined Use of Methylergonovine and Oxytocin during Caesarean Section in the Prevention of Post-partum Haemorrhage. Basic Clinical Pharmacol Toxicol. 2016;118(5):338-43.

14. Gallos ID, Williams HM, Price MJ, Merriel A, Gee H, Lissauer D, Moorthy V, Tobias A, Deeks JJ, Widmer M, Tunçalp Ö, Gülmezoglu AM, Hofmeyr GJ, Coomarasamy A. Uterotonic agents for preventing postpartum haemorrhage: a network meta-analysis. 
Cochrane Database of Systematic Reviews. 2018;4:CD011689.

15. NICE guidelines

for

$\mathrm{PPH}$ https://pathways.nice.org.uk/pathways/intrapartumcare/care-in-third-stage-of-labour.pdf. Last accessed on $18^{\text {th }}$ January, 2021.

16. Green-top Guidelines No 52. https://obgyn.onlinelibrary.wiley.com/doi/10.1111/to g.12384. Last accessed on $18^{\text {th }}$ January, 2021.

17. Paily VP, Ambujam K, Rajasekharan Nair V, Thomas B. Confidential review of maternal deaths in Kerala: a country case study. BJOG. An International Journal of Obstet Gynaecol. 2014;121:61-6.

Cite this article as: Somanathan R, Balu M, Jacob E, Illickal SM. A randomised controlled study for the prevention of post-partum haemorrhage with oxytocin plus methyl ergometrine versus oxytocin alone in the third stage of labour. Int J Reprod Contracept Obstet Gynecol 2021;10:1906-13. 